\title{
Ethics without abstraction: squaring the circle
}

\author{
Daniel Callahan The Hastings Center, New York, USA
}

The debate on euthanasia and physician-assisted suicide has brought out an onslaught of what might be called abstraction-bashing. One author criticized my writings on euthanasia by saying that "moral reasoning is more objectionable when it is abstract than when it is merely wrong. For abstractness all but guarantees error by missing the human predicament that needs to be addressed ...". ${ }^{1}$ Dr Howard Brody, commenting on physician-assisted suicide (PAS) has written that the "moral tensions" of that issue "require more reliance on negotiation, compromise, and practical reasoning, and less on abstract ethical theory". 2

I am not interested here in taking up the problem of euthanasia and PAS or defending myself on those issues. I want instead to focus on the critique of "abstract" ethics. My private response in both cases to that word "abstract" was, "Oh no, here we go again - that old chestnut". Hardly a month has gone by during my thirty-odd years in bioethics when somebody or other has not complained about ethical abstractions, often enough doctors against philosophers or lawyers, but sometimes one philosopher against another, a caring contextualist feminist, say, against a duty-ridden Kantian deontologist. Human experience, we are told, puts the lie to ethical abstractions, showing them to be at worst rigid and cruel, at best naive and insensitive to the richness and complexity of life.

I could also hardly fail to note during those years that every field has its equivalent criticisms: practising physicians deride the abstract ivory-tower view of medicine displayed by medical school instructors, "front line" soldiers "in the trenches" detest generals who give unrealistic orders from rear-echelon safety, politicians joke about economists who "can't balance their own checkbooks", and parents with bratty children mock experts who say that one should simply be firm and patient with them. Almost everyone, in short, has good sport in hitting someone else over the head with what the "real" world is actually like, and why abstractions fail to capture it.

So far as ethics is concerned, however, the complaint against abstractions usually rests on two misconceptions. One of them is a mistake about the nature of ethics, and the other an error about the deliverances of experience. Good - and useful ethics will and must entail a high degree of abstractness. What William James called the "blooming, buzzing confusion" of actual experience cannot be ordered or morally interpreted without the help of abstractions. The aim of ethical theory is to provide us with some general, high-level abstractions that will help us make sense of experience. For as revealing as life "in the trenches" may be, it does not tell its own story; that is what concepts, perspectives, and abstractions help us to do. Just as two physicians with exactly the same set of "nitty-gritty" experiences with procreation and childbirth can morally differ on abortion, so can two physicians who had had identical experiences with dying patients differ about euthanasia. Is Dame Cicely Saunders an opponent of euthanasia because she is a victim of abstractions, lacking first-hand contact with dying patients, unable to appreciate practical reason? Or, to switch examples, are opponents of capital punishment (as I am) suckers for moral abstractions because we have never had any personal experience with serial killers? Must one have such an experience to be a credible opponent of capital punishment? Or is our unswerving opposition yet another case of abstractionitis?

\section{Three observations}

Before exploring that general line of thought further, it is necessary to make three observations. First, not only is the word "abstraction" often used as a term of criticism of theoreticians by practitioners, it is no less frequently used these days as a form of tendentious advocacy against moral rules or principles that someone does not like. The form of the argument will be at once recognizable: if only supporters of the controverted rule (for example, opposition to euthanasia) would get their head out of the clouds (another favourite expression), give up moral abstractions, and look at the real world, they would see the light.

Now where have I heard that kind of argument before? Oh yes, now I remember. Thirty years ago it was thought equally insensitive and naive to believe that cancer patients should be told the truth even if 
they said they wanted to hear it. Only moral lunatics would defend a moral rule of truth-telling to such patients. And it was considered positively outrageous that anything so abstract as the principle of "informed consent" should always and everywhere govern human subject research. Only someone ignorant of the subtleties of medical research, and inexperienced in dealing with uneducated and emotional patients, could ever give credibility to such a crazy, truly celestial kind of moral abstraction. Now it is opponents of euthanasia and physician-assisted suicide who are this season's target, guilty as charged of perpetrating moral abstractions.

The second observation is that there is an entire class of current moral rules and principles, no less abstract, say, than the rule against euthanasia, that no one publicly challenges at all. I have never heard anyone accused of abstraction-mongering in supporting hard and exceptionless, highly abstract rules against rape, genocide, racism, sexism, and religious discrimination. Is this because "real" life "in the trenches" on those matters is somehow utterly lacking in complexity, unusual circumstances, and occasional dilemmas? Up until a few decades ago, sophisticated racist Americans argued that, given the deep moral differences of opinion on discrimination and segregation, negotiation, compromise, and practical reason was called for, not the kind of abstract moral theory that simply wanted them banned and forbidden. That siren-song was eventually resisted, the argument for negotiation and compromise rejected. We have all been better off for standing firm, hanging on to our abstractions.

The point is that there are some, perhaps many, moral abstractions of which most people approve. We like and agree with the moral abstractions that guide us on some matters - indeed we are likely to think them tough and realistic, the fruit of hardlearned nasty historical lessons; and we have become smart enough not to be seduced by those who want us to give up or compromise those principles in the name of context, ambiguity, multiculturalism, sensitivity or whatever other version of moral complexity can be thrown into the breach against the devil of abstractionism.

The third observation is to note how frequently a charge of abstraction-dumping is accompanied by that most ancient of all moral nostrums, the "everybody's-doing-it" argument. Look around you child: don't you see that doctors almost always lie to cancer patients about the prospects for successful chemotherapy, that researchers rarely disclose to subjects the full hazards of their experiments, and that compassionate doctors daily, commit secret euthanasia and covertly assist people to commit suicide? Wake up! Get with it! All that anti-abstractionists ask is to cut out the hypocrisy, to tell it the way it is, to stop kidding ourselves, to face up to THE WAY THINGS ARE, etc, etc. It is almost a ritual incantation, but translated into ordinary language this kind of talk usually means: because everyone is doing it, therefore it must be the right thing to do; and, besides, I agree with what they are doing anyway.

I mention these three observations simply to note that, like much else, ethical arguments can be put to political and self-interested uses: ethical abstractions are bad if they are $m y$ abstractions stemming from my morally incorrect reasoning, but perfectly fine if they are your abstractions based on your higher-grade insight into the way things really are (really, really, that is). So, a suggested rule-of-thumb: if someone accuses you of spreading moral abstractions around like some kind of virus, it is perhaps you who should put on the sterile face-mask, not the moral diagnostician who claims to have seen the fatal symptoms because of his or her superior ethical skills. He, that is, may have a problem, not you.

\section{Theory and experience}

Let me return to the central issue, the place and value of moral abstractions. Towards that end, I want to distinguish between moral progress in general and moral judgment in particular. I said at the outset that moral abstraction is necessary in order to make sense of human experience. It is the way we extract from what is, the way life presents itself in the raw, to fashion what ought to be; and "what ought to be" will usually be articulated in our language, consciousness, and legitimated practices as general, broad, abstract ideas or propositions: "Do unto others as you would have them do unto you", for instance, or "Thou shalt not commit rape", or "Racial discrimination is wrong", or "Informed consent is always required in the case of hazardous medical research".

Moral progress consists in developing a defensible set of moral abstractions, the fruit of hard thought and carefully analyzed experience over a long period of time. That is why no one considers a blanket condemnation of slavery, or child-selling, or gratuitous cruelty, to be harmful moral abstractions. They seem realistic moral rules and absolutely right. They all rest, in the end, on a still higher moral abstraction, the respect we owe persons. If our societies come eventually to accept euthanasia or physicianassisted suicide, it will not be because of overcoming an abstract rule against those practices. It will be because we have replaced one previously serviceable abstraction with another, thought to be even better, no doubt that most popular abstraction called the "right to self-determination". And that will be accounted progress by some (though not by me).

If moral progress in general consists of developing and refining useful ethical abstractions, good moral judgment in particular will almost always consist of working back and forth between our abstract principles and the actualities of experience, what John Rawls has called the process of "reflective equilibrium". That is only a technical term for what 
(almost) every moral philosopher from Aristotle forward has well understood: that there is always a gap between theory and experience, moral rules and human complexity, thinking and doing. A good moral judgment is one that well and prudently navigates that gap, bringing accepted moral abstractions to bear on novel or complex circumstances - and sometimes finding the abstractions wanting; and in other circumstances standing firm with the abstractions in the face of temptations to evade or change them. The problem is not with abstractions as such. It is in knowing which to keep, which to modify, and which to abandon.

Abstractions, then, are the very stuff of ethics, for better or worse. I would, therefore, most humbly suggest the following: let us now and forever bury charges of "abstraction".

Is that likely to happen? Of course not. No well burnished, polemically serviceable, shop-worn cliché ever gets buried. Moreover, there surely will be at least one reader out there who will accuse me of having a most abstract view of ethics, curable if only I would open my eyes to what's going on around me, come down to earth...

Daniel Callahan is President of The Hastings Center and the author, most recently, of The Troubled Dream of Life: In Search of a Peaceful Death (Simon $\mathcal{E}$ Schuster).

\section{References}

1 Lachs J. When abstract moralizing runs amok. The Fournal of Clinical Ethics 1994; 5, 1: 10.

2 Brody H. Assisted death - a compassionate response to a medical failure. The New England Fournal of Medicine 1992; 327, 19: 1384 .

\section{News and notes}

\section{Poynter Center announcements}

A conference entitled Ethical Issues of Animal Research will be held from May 30-June 1 at the Poynter Center for the Study of Ethics and American Institutions, Indiana, Bloomington, Indiana. Topics will include: The moral standing of animals, including religious perspectives; major philosophic arguments for and against animal research, and genetic manipulation of animals.

For further information contact Kenneth D Pimple, PhD, Poynter Center for the Study of Ethics and American Institutions, Indiana University, 410 North Park Avenue, Bloomington, Indiana 47405. Tel:
(812) 855-0261; fax: (812) 855-3315; E-mail: pimple@indiana.edu.

The center has also recently published a 100-page booklet of materials for teaching the responsible conduct of science in college and university science courses. Moral Reasoning in Scientific Research: Cases for Teaching and Assessment is available at cost for use by educators. For more information contact Dr Pimple at the above address, or, if you wish to buy the booklet outright, send a cheque for US\$7.00 made out to the Poynter Center, to him at the above address. 